\title{
A AUSÊNCIA DE TRANSPARÊNCIA DOS ENTES MUNICIPAIS NO QUE SE REFERE AOS REPASSES DE RECURSOS PÚBLICOS A ENTIDADES PRIVADAS NAS ÁREAS DA SAÚDE E EDUCAÇÃO: UMA ANÁLISE DAS INFORMAÇÕES LANÇADAS NOS PORTAIS DA TRANSPARÊNCIA
}

\author{
ERTEL, R. M.1; RECK, J. R. ${ }^{2}$
}

PALAVRAS CHAVE: Transparência. Acesso à Informação. Recursos Públicos. Transferências. Saúde. Educação.

\section{RESUMO}

0 presente artigo aborda o histórico e a finalidade da Lei de Acesso à Informação, bem como se propõe a analisar os Portais da Transparência de quatorze municípios gaúchos, dentre eles os dez mais transparentes (de acordo com o Ranking da Transparência elaborado pelo Tribunal de Contas do Estado do Rio Grande do SUL - TCE RS - em 2015), e também aqueles nos quais a Universidade de Santa Cruz do Sul - UNISC - possui campi. A metodologia adotada foi a bibliográfica, bem como se utilizou do processo de visitação aos Portais da Transparência e visitação aos sites das prefeituras de cada um dos municípios mencionados. Como resultados, se percebeu que, com relação aos repasses públicos a entidades privadas nas áreas da saúde e educação, as informações constantes nos sites são precárias e de difícil entendimento pelo cidadão comum, dificultando o exercício do controle do social. Ademais, ao praticar a transparência passiva por meio do e-SIC, apenas quatro municípios retornaram à solicitação, o que demonstra uma grave ofensa ao exercício da cidadania.

\section{THE LACK OF TRANSPARENCY IN PUBLIC HEALTH AND EDUCATION SERVICES: AN ANALYSIS OF THE INFORMATION RELEASED IN THE TRANSPARENCY PORTALS}

\author{
KEYWORDS: Transparency Access to information. Public Resources. Transfers. Health. Education.
}

\begin{abstract}
This article deals with the history and purpose of the Law off Access to Information, as well as proposing to analyze the Transparency Portals of 14 municipalities in Rio Grande do Sul, among them the ten most transparent ones (in accordance of the Transparency Ranking prepared by the Court of Auditors of the State of Rio Grande do Sul - TCE RS in 2015), as well as those in which the University of Santa Cruz do Sul - UNISC - has campuses. The methodology used was the bibliographical one, as well as the visitation process into the Transparency Portals and visitation of the sites of prefectures of each of the mentioned municipalities. As a result it was noticed that, in relation to public transfers to private entities in the areas of health and education, the information on the sites is precarious and difficult to understand by ordinary citizens, making it difficult to exercise social control. In addition, in practicing passive transparency through eSIC, only four municipalities returned to the request, which shows a serious offense to the exercise of citizenship.
\end{abstract}

\footnotetext{
${ }^{1}$ Acadêmica do curso de Direito da Universidade de Santa Cruz do Sul.

2 Docente do Departamento de Direito da Universidade de Santa Cruz do Sul.
} 


\section{INTRODUÇÃO}

O presente artigo centraliza seu estudo na Lei de Acesso à Informação, bem como na análise dos Portais da Transparência dos municípios mais transparentes do Estado do Rio Grande do Sul, conforme ranking elaborado pelo Tribunal de Contas do Estado do RS - TCE RS - em 2015 (ano escolhido devido a data do início da pesquisa - abril de 2017, em que o órgão ainda não havia divulgado o ranking de 2016), mais os municípios nos quais a Universidade de Santa Cruz do Sul atua. 0 problema de pesquisa é o seguinte: por meio de consulta aos Portais da Transparência dos municípios, bem como ao site do Tribunal de Contas do Estado do RS, é possível verificar se estão sendo disponibilizados ao cidadão os percentuais totais dos recursos públicos repassados às entidades privadas nas áreas da saúde e educação?

Já a hipótese é no sentido de que não são disponibilizadas as informações de forma clara e transparente no que diz respeito aos recursos públicos repassados às entidades privadas. 0 tema, por sua vez, é multidisciplinar, pois envolve legislação federal concernente ao Direito Administrativo e Constitucional e a aplicação municipal dos decretos regulamentadores, bem como o seu impacto no controle social da transparência pública. A contemporaneidade é o marco delimitador temporal do trabalho, principalmente a partir da edição da Lei $n^{\circ} 12.527 / 2011$, mais conhecida como Lei de Acesso à Informação.

Como justificativa social do presente estudo, pretende-se contribuir com o exercício do controle social, por meio da testagem do atendimento ao cidadão pelos entes públicos. Já como justificativa científica, a presente abordagem é estratégica quanto às atuais formas de disponibilização de dados e atendimento de solicitações, apontando problemas e sugerindo mudanças quanto à disposição dos Portais da Transparência e cumprimento da Lei de Acesso à Informação.

Em sendo confirmada a hipótese do problema de pesquisa, se analisará o controle social quando da fiscalização das entidades privadas que recebem recursos públicos, bem como se as transferências eventualmente caracterizam a privatização da saúde e da educação públicas. Da mesma forma, se analisará a (provável) dificuldade de fiscalização por parte do cidadão, na ausência de cumprimento da transparência esperada quanto aos repasses públicos às entidades privadas.

\section{A LEI DE ACESSO À INFORMAÇÃO E SUA EXTENSÃO ÀS ENTIDADES PRIVADAS}

O acesso à informação é uma figura essencial para o exercício da cidadania, já que é por meio dele que fica possibilitado à sociedade acompanhar, participar, avaliar, questionar e ocupar seu espaço perante a estrutura e poderes que constituem o Estado (DEIENNO, SANTOS, 2014, p. 17). 0 direito à informação, mesmo garantido constitucionalmente (art. $5^{\circ}$, XIV da Constituição Federal), 
clamava por uma regulamentação legal para que chegasse a um conceito de informação, dependendo de uma lei infraconstitucional para preencher a lacuna existente, a fim de assegurar ao cidadão o seu direito, positivando a forma, o suporte, os meios e tipos de informações disponíveis para acesso. Ademais, o art. $5^{\circ}$, inciso XXXIII, também da Constituição Federal, já previa o direito de todos os cidadãos de obter dos órgãos públicos as informações de seu interesse.

Desta forma, sobreveio a Lei $\mathrm{n}^{\circ}$ 12.527/2011, mais conhecida como Lei de Acesso à Informação (LAI), com o intuito de estabelecer o procedimento para obter informações, bem como de exigir das entidades e órgãos públicos a disponibilização à sociedade das informações produzidas pela Administração Pública. De acordo com o seu art. $2^{\circ}$, a lei também se aplica às entidades privadas sem fins lucrativos que venham a receber recursos públicos diretamente do orçamento ou por meio de subvenções sociais, contrato, termo de parceria, convênios, e similares, para realização de ações de interesse público. Desta forma, tais entidades ficam submetidas à publicidade referente a parcela dos repasses públicos e sua consequente destinação (BRASIL, www.planalto.gov.br, 2011).

Ao incluir as entidades privadas na Lei de Acesso à Informação, resta claro o intuito desta que, conforme Riquinho (2013), garante e incentiva a participação da sociedade nos orçamentos, restando também garantido pela lei, a obrigação do orçamento passar pela aprovação popular em todos os seus estágios, inclusive o da execução. Como forma de revigorar a cidadania, "a transparência estimula a participação social, a informação divulgada aproxima sociedade da gestão exercida por seus representantes" (FIGUEIREDO, SANTOS, 2013, p. 6).

Assim, como a Lei de Acesso à Informação deve ser cumprida por todos os seus destinatários e em todas as esferas de poder, a regulamentação local é necessária para determinar procedimentos que, de acordo com a norma geral, leve em consideração as especificidades de cada ente público, traduzindo regras mais genéricas e abstratas da lei federal para as peculiaridades do ente local interessado em dar maior efetividade ao exercício do direito de acesso às informações públicas (ENAP, www.enap.gov.br). Portanto, em âmbito regional, no Estado do Rio Grande do Sul a matéria foi regulamentada por meio do Decreto $n^{\circ}$ 49.111/12 (RIO GRANDE DO SUL, 2012, http://www.centraldeinformacao.rs.gov.br).

\section{A INSTITUIÇÃO DOS PORTAIS DA TRANSPARÊNCIA E O RANKING DA TRANSPARÊNCIA DOS} MUNICÍPIOS GAÚCHOS

Antes mesmo da edição da LAI, no ano de 2004, houve a criação do Portal de Transparência pela Controladoria-Geral da União (CGU), com a finalidade de combater a corrupção e de constituir um canal pelo qual o cidadão poderia acompanhar o orçamento e a execução financeira dos programas de governo, primeiramente em âmbito federal. A consulta ao Portal visava possibilitar a verificação de dados acerca dos repasses públicos do Governo Federal aos Estados, Municípios e 
Distrito Federal, bem como diretamente ao cidadão, e também as informações sobre os gastos realizados pelo próprio Governo em compras, contratações, convênios e etc. 0 respectivo Portal veio justamente com o objetivo de aumentar a transparência da gestão pública, propiciando o acesso à informação de forma facilitada ao cidadão (CONTROLADORIA-GERAL DA UNIÃO, www.cgu.gov.br).

A instituição do Portal da Transparência, bem como a entrada em vigor da Lei de Acesso à Informação, neste contexto, e considerando a fiscalização exercida pelos Tribunais de Contas de cada Estado nos Portais de cada município, resultaram na implementação do Ranking da Transparência dos Municípios pelo Tribunal de Contas do Estado do Rio Grande do Sul. 0 referido ranking tem por objetivo reconhecer os esforços dos Poderes Executivo e Legislativos Municipais no que diz respeito à transparência, em conformidade com os resultados de uma avaliação de seus portais oficiais (TRIBUNAL DE CONTAS DO ESTADO, www.tce.rs.gov.br).

0 ranking, diante das informações retiradas do site do TCE-RS, utiliza vinte e dois critérios, por meio dos quais é verificado se há atendimento pelos entes públicos municipais das exigências contidas na Lei de Acesso à Informação e na Lei de Responsabilidade Fiscal, nos termos supramencionados. Importante referir que se optou pelo ranking elaborado pelo TCE RS, por este possuir critérios mais abrangentes e por contemplar exclusivamente todos os municípios gaúchos (em comparação a demais rankings existentes).

Em não sendo localizado no Portal da Transparência a informação desejada, há duas opções para o acesso à informação (denominada transparência passiva): a pessoa interessada pode formalizar o seu pedido por intermédio de um formulário próprio disponível na unidade física do Serviço de Informações ao Cidadão (SIC) do órgão responsável por guardá-la, ou, ainda, por intermédio da seção reservada em sítios na internet (e-SIC). A prestação da informação, em não podendo ser imediata, deverá ser respondida em até 20 (vinte) dias, prorrogáveis uma vez por mais 10 (dez) dias (BRASIL, www.planalto.gov.br, 2011).

Oportuno salientar que "a Lei de Acesso à Informação busca naturalizar o controle social pela efetiva participação popular e fazer cumprir o dever de transparência passiva" (NICOLA, GUEDES, SILVA, 2014, p. 50). Dentro deste raciocínio, a LAl busca assegurar o acesso à informação a todos os interessados, mesmo, por vezes, sendo necessário o cadastramento dos dados de documentos de identificação e do endereço da pessoa solicitante, todavia, a identificação não pode inviabilizar o pedido.

A Lei de Acesso à Informação exige que fiquem disponíveis em sítios na internet bancos de
dados atualizados sobre os gastos com estrutura organizacional (cargos, salários, etc.),
programas e ações em desenvolvimento, andamento de projetos, obras públicas e
procedimento processos de licitação, com editais e resultados, registros de subsídios, repasses
e transferências de recursos, detalhes de auditorias e fiscalizações; enfim, não há limites para
as informações a serem solicitadas e isso significa exercício pleno de direito de petição como
meio de controle social pela participação. Como toda regra tem exceção, estão dispensados da
divulgação pela internet apenas os Municípios com menos de 10 (dez) mil habitantes; contudo,
ainda assim devem dispor de Serviço de Informações ao Cidadão (SIC) dentro de cada órgão 
responsável pelas informações solicitadas, com a divulgação de endereço e horário de atendimento ao público bem definidos (NICOLA, GUEDES, SILVA, 2014,p. 50).

Deste modo, partiu-se do pressuposto que a Lei de Acesso à Informação prevê que as entidades privadas sem fins lucrativos que recebam recursos públicos para a prática de ações de interesse público, ou entidades que tenham parceria e/ou convênios com o governo, também devem publicar as informações sobre os montantes recebidos e a sua respectiva destinação (TRIBUNAL DE CONTAS DO ESTADO, www.tce.rs.gov.br). Portanto, foram selecionados os dez municípios considerados os mais transparentes do Estado (de acordo com o ranking do TCE RS - 2015), quais sejam: Porto Alegre, Novo Hamburgo, Canoas, Picada Café, Passo Fundo, Venâncio Aires, Farroupilha, São Pedro do Sul, Ipê e Feliz, respectivamente; mais os municípios em que a UNISC atua (Santa Cruz do Sul, Sobradinho, Montenegro e Capão da Canoa).

Ademais, a fim de nortear e tornar viável a verificação nos sites, optou-se por fiscalizar as transferências a entidades privadas pelos municípios tão somente no que se refere aos repasses nas áreas da saúde e educação, já que ambas possuem percentuais mínimos fixados constitucionalmente para investimento, sendo quinze por cento em saúde (art. $7^{\circ}$ da Lei Complementar n. 141/2012) e vinte e cinco por cento em educação (art. 212 da Constituição Federal).

Assim, partindo-se de todos os pressupostos trazidos pelo que se entende de direito ao acesso à informação, conforme supramencionado, os ora objetivos da análise dos Portais são: analisar de forma experimental (por meio da efetiva consulta) se há informação clara e de fácil acesso acerca das transferências realizadas dentro dos Portais da Transparência; e se os repasses de recursos públicos a entidades privadas ocorrem dentro dos percentuais mínimos estabelecidos constitucionalmente para gastos em saúde e educação, ou se dão no excedente; bem como, analisar se esse repasse acaba por caracterizar uma privatização da prestação dos serviços públicos, e como isso interfere no controle social dessas entidades privadas.

Oportuno mencionar que essa prestação de serviços é eminentemente pública, porém, é possível a atuação privada de forma subsidiária. Neste viés, prevê o Art. 199 da Constituição Federal, que as instituições privadas podem participar de forma complementar do sistema único de saúde, mediante contrato ou convênio, por isso justifica-se a análise de eventual privatização.

\section{A AUSÊNCIA DE TRANSPARÊNCIA QUANTO AOS REPASSES ÀS ENTIDADES PRIVADAS:} OBSTÁCULOS AO EXERCÍCIO DO CONTROLE SOCIAL

Diante da consulta ao site do TCE RS, é possível afirmar que está disponível o percentual total que cada município gastou em saúde e educação nos anos de 2015 e 2016, porém, de acordo com consulta realizada em junho/agosto de 2017, não há disponibilização clara no site do TCE e 
nem opção de busca específica que indique qual a parcela deste percentual que fora repassado às entidades privadas pelos municípios referidos.

Em continuidade ao acesso às informações, e partindo-se para o exercício da transparência passiva (diante da ausência de êxito quanto à transparência ativa), utilizou-se a ferramenta de solicitação de acesso a informações constante no site do TCE RS, encaminhando a este órgão as seguintes perguntas: "Qual foi o percentual repassado a entidades privadas (dentro de cada município selecionado), nos anos de 2015 e 2016, nos setores da saúde e educação?" e "Em qual local do site é possível ter acesso a esse dado?"

A resposta do TCE RS se deu por telefone e por e-mail, dentro do prazo previsto em lei (vinte dias), sendo que foi informado em 21 de agosto de 2017 a impossibilidade de atendimento à solicitação, por não possuírem a informação requerida. Inclusive, por e-mail, o TCE RS informou que “infelizmente, um dos critérios com menor índice de atendimento é o que verifica se existem informações sobre 'Transferências realizadas pelo Município a outra entidade e órgão público e privados"”.

Ainda, o TCE RS informou que poucas prefeituras (dentro dos quatorze municípios selecionados) haviam publicado informações quanto às transferências realizadas em 2016, indo ao encontro da dificuldade encontrada quando do exercício da transparência ativa. Ainda, informaram que os dados lançados no site do órgão fiscalizador são de exclusiva responsabilidade de cada ente público municipal, e que "o TCE-RS não faz nenhuma análise prévia ou validação das informações ali disponíveis, razão pela qual todos os dados ali disponíveis são de exclusiva responsabilidade do ente público titular."

Em sua resposta, o TCE-RS também afirmou que o nível de detalhamento desses registros depende do modo que cada ente o lança no sistema, inviabilizando uma pesquisa com resultados uniformes, já que são diversas rubricas e empenhos lançados, não havendo padronização. Ademais, o próprio órgão encaminhou a seguinte tabela: 


\begin{tabular}{|c|c|}
\hline Município & $\begin{array}{l}\text { Publica informaçōes sobre Transferências } \\
\text { *item } 04 \text { do questionário }\end{array}$ \\
\hline Porto Alegre & Não \\
\hline Novo Hamburgo & Sim - mas não tem histórico \\
\hline Canoas & Não \\
\hline Picada Café & $\begin{array}{l}\text { Item não avaliado pela auditoria em } 2016 \\
\text { "em } 2015 \text { recebeu "Sim" }\end{array}$ \\
\hline Passo Fundo & Não \\
\hline Venâncio Aires & $\begin{array}{l}\text { Sim - não tem informações atualizadas } \\
\text { *em } 2015 \text { "Sim" }\end{array}$ \\
\hline Farroupilha & Não \\
\hline São Pedro do Sul & Sim \\
\hline Ipê & $\begin{array}{l}\text { Item não avaliado pela auditoria em } 2016 \\
\text { "em } 2015 \text { recebeu "Sim" }\end{array}$ \\
\hline Feliz & Sim \\
\hline Santa Cruz do Sul & Não \\
\hline Sobradinho & Não \\
\hline Capão da Canoa & Sim \\
\hline Montenegro & Não \\
\hline
\end{tabular}

Por meio de consulta aos sítios de cada município ora objeto de estudo, nota-se que há transferência na prestação de serviços públicos, ao menos em parte, a diversas entidades privadas (denominadas como pessoas jurídicas dentro dos Portais, na aba das despesas) nas áreas da saúde e da educação, porém sem disponibilização do percentual total correspondente.

Portanto, diante do retorno negativo do TCE RS, utilizou-se da transparência passiva dentro de cada município (sendo inclusive uma sugestão do próprio órgão fiscalizador), encaminhando a seguinte pergunta sobre o percentual repassado às entidades privadas, no final de agosto de 2017: "Participo de um projeto de pesquisa vinculado à Universidade de Santa Cruz do Sul - UNISC, no qual estudamos os percentuais aplicados em saúde e educação nos municípios, utilizando, para tanto, consultas ao Portal da Transparência. Um dos objetivos do grupo é estudar também a relação público $x$ privada, todavia, o TCE nos informou que não possui a informação acerca do percentual total repassado pelos municípios às entidades privadas (ONGs, OSCIPS, OS, fundações, e etc) no que se refere à saúde e educação nos anos de 2015 e 2016, sugerindo questionar a cada município em estudo. Assim, questiono: qual o valor do percentual total gasto repassado às entidades privadas no que se refere às despesas na área da saúde e educação do município (isto é, qual o percentual total correspondente aos repasses realizados por meio de contratos e convênios), em 2015 e 2016?"

Transcorrido o prazo previsto pela LAI (vinte dias, prorrogáveis por mais dez), apenas quatro municípios responderam dentro do prazo, ou seja, houve atendimento da solicitação realizada pelo eSic somente por Porto Alegre, Picada Café, Ipê e Santa Cruz do Sul. Os demais municípios sequer responderam à solicitação, com exceção de Farroupilha, que encaminhou e-mail fora do prazo dizendo que "no site do TCE-RS você poderá encontrar todas informações", ferindo gravemente a LAI, 
que prevê em seu art. $11, \S 1^{\circ}$, III e $\S 6^{\circ}$ que a entidade deverá informar ao solicitante a forma pela qual poderá consultar ou obter a informação requerida, indicando o caminho específico para tanto, ou então remetendo o requerimento ao órgão que detém a informação (BRASIL, www.planalto.gov.br, 2011). Mesma determinação consta nos parágrafos do art. $9^{\circ}$ do Decreto $n^{\circ} 49.111 / 12$.

Oportuno mencionar algumas peculiaridades percebidas: o município de Novo Hamburgo não possibilitou a consulta do andamento do processo pelo Portal da Transparência, eis que o CPF informado na solicitação não está cadastrado no município, mas também não foi encaminhado o andamento por e-mail. No que se refere ao CPF, resta descumprida a previsão do art. $10, \S 1^{\circ}$ da lei 12.527/2011, que determina que a identificação não pode inviabilizar o pedido, e, por óbvio, a consulta ao andamento do processo também.

0 município de Canoas, por sua vez, informou um login para acesso ao site, possibilitando consultar o andamento, porém, transcorrido o prazo legal, restou bloqueada a conta cadastrada (sem o atendimento da solicitação), e o site impossibilita a abertura da página que dá acesso à reativação da conta pelo número do CPF.

Já no site da prefeitura de Venâncio Aires, ao tentar consultar o andamento do processo pelo número cadastrado, este sequer é localizado, mesmo havendo confirmação por e-mail e por telefone do recebimento da solicitação, com consequente envio de número de protocolo. Ainda, o município de Feliz, tendo confirmado o recebimento da solicitação por e-mail, não informou um número de protocolo/processo, bem como, ao consultar o relatório de pedidos realizados do ano de 2017 disponibilizado em seu site, consta que nenhum pedido de acesso à informação foi feito pelo e-Sic no decorrer do ano, apesar da solicitação relatada e recebida (PREFEITURA DE FELIZ, www.feliz.rs.gov.br).

Por fim, os demais municípios não deram retorno, constando que a solicitação ainda está em andamento, tendo sido transferida ao setor responsável, ou encerrada como se houvesse sido atendida (sem, contudo, apresentar resposta ou mesmo alguma negativa).

Oportuno salientar que, após o prazo transcorrido, foi reiterado o pedido por e-mail às Prefeituras de Novo Hamburgo, Venâncio Aires, Feliz (que apresentaram problemas na consulta) e Capão da Canoa (que informava no site que havia atendido à solicitação, sem na verdade apresentar resposta), e mesmo assim não houve retorno.

Já acerca dos municípios que responderam ao questionamento dentro do prazo previsto em lei, quais sejam, Porto Alegre, Ipê, Picada Café e Santa Cruz do Sul, segue a representação gráfica abaixo para expor as respostas obtidas: 
Percentuais repassados pelos municípios consultados

\begin{tabular}{|c|c|c|}
\hline $\begin{array}{c}\text { Municípios que } \\
\text { responderam ao e-SIC }\end{array}$ & \% gasto em saúde & \% gasto em educação \\
\hline \multirow[t]{2}{*}{ Porto Alegre } & $\begin{array}{c}2015-4,73 \% \text { repassado } \\
\text { a entidades privadas, } \\
\text { dentro de um total de } \\
20,85 \%\end{array}$ & $\begin{array}{c}2015-9,53 \% \text { repassado } \\
\text { a entidades privadas, } \\
\text { dentro de um total de } \\
27,73 \%\end{array}$ \\
\hline & $\begin{array}{c}2016-2,5 \% \text { repassado a } \\
\text { entidades privadas, dentro } \\
\text { de um total de } 28,64 \%\end{array}$ & $\begin{array}{c}2016-10,15 \% \text { repassado } \\
\text { a entidades privadas } \\
\text { dentro de um todo de } \\
26,52 \%\end{array}$ \\
\hline \multirow[t]{2}{*}{ Picada Café } & $\begin{array}{l}2015 \text { - 8,45\% do total da } \\
\text { despesa gasta com saúde }\end{array}$ & $\begin{array}{c}2015 \text { - 11,45\% do total da } \\
\text { despesa gasta com } \\
\text { educação }\end{array}$ \\
\hline & $\begin{array}{l}2016 \text { - 9,13\% do total da } \\
\text { despesa gasta com saúde }\end{array}$ & $\begin{array}{c}2016 \text { - 11,10\% do total da } \\
\text { despesa gasta com } \\
\text { educação }\end{array}$ \\
\hline \multirow[t]{2}{*}{ Ipê } & $\begin{array}{c}2015 \text { - 11,422\% do total } \\
\text { da despesa gasta com } \\
\text { saúde }\end{array}$ & $\begin{array}{c}2015 \text { - 1,157\% do total da } \\
\text { despesa gasta com } \\
\text { educação }\end{array}$ \\
\hline & $\begin{array}{c}2016-17,675 \% \text { do total } \\
\text { da despesa gasta com } \\
\text { saúde }\end{array}$ & $\begin{array}{c}2016-0,932 \% \text { do total da } \\
\text { despesa gasta com } \\
\text { educação }\end{array}$ \\
\hline Santa Cruz do Sul & $\begin{array}{c}2016 \text { - valor total gasto } \\
\text { em saúde: } \mathrm{R} \$ \\
136.665 .758,82 \\
\text { Valor total repassado a } \\
\text { entidades privadas: } \mathrm{R} \$ \\
79.448 .460,91\end{array}$ & $\begin{array}{l}\text { Redirecionado para o site } \\
\text { do FNDE - SIOPE }\end{array}$ \\
\hline
\end{tabular}

Fonte da tabela: informações repassadas por e-mail.

Obtém-se como resultados (contidos de forma resumida no quadro acima), no que concerne ao exercício do controle social, que: 1) Porto Alegre, no que se refere aos gastos em saúde, realiza repasses a entidades privadas de forma complementar, transferindo valores apenas no excedente, isto é, não necessita das transferências para atingir o percentual mínimo vinculado de gasto em saúde; 2) no que se refere à educação, o repasse se dá em montante mais significativo em Porto Alegre, sendo necessárias as transferências a entidades privadas para se atingir o percentual mínimo vinculado; 3) os municípios de Picada Café e Ipê realizam transferências a entidades privadas em baixo percentual, dentro do todo gasto em saúde e educação, representando pequena parcela de repasses; 4) Santa Cruz do Sul repassa mais da metade dos gastos em saúde para entidades privadas, caracterizando uma terceirização/privatização desse serviço público, e, por óbvio, repassa percentuais dentro do necessário para atingir o percentual mínimo constitucional vinculado; 5) ainda, a Prefeitura de Santa Cruz do Sul retornou apenas com os valores correspondentes, cabendo 
ao cidadão fazer a interpretação do percentual; 6) não foi conclusiva a resposta fornecida no que se refere às despesas em educação por este município, como adiante se explicitará.

No que se refere à área da saúde, foram feitas perguntas adicionais por e-mail ao município de Santa Cruz do Sul, sendo requerida resposta mais completa justamente por se ter um interesse maior neste, eis que é a sede da presente instituição de ensino. Assim, foi obtido como resposta o seguinte:

1. Qual o valor total gasto com saúde no Município no exercício 2016? R\$ $136.665 .758,82$

2. Qual o valor total repassado a entidades privadas de saúde em 2016 ? R $\mathbf{7 9 . 4 4 8 . 4 6 0 , 9 1}$ (Considerados hospitais, laboratórios, consórcio de saúde, ...)

3. Quais são as formas de controle dos gastos/recursos repassados em atividade privada? 0 controle é realizado com a conferência dos relatórios de produção e prestação de contas realizada pelas entidades. A secretaria conta também com enfermeira auditora e médica auditoria que realizam auditoria in loco.

4. Qual o valor total gasto em despesas com órgãos públicos de saúde, excluindo os repasses para entidades privadas e incluindo os gastos com servidores? R\$ 57.217.297,91

5. Qual o valor gasto em servidores na saúde e qual o valor gasto em outras despesas de saúde? Folha servidores $\mathrm{R} \$ 26.906 .357,16$

Encargos R\$ 5.834.163,16

Terceirizados (por meio de convênio) R\$ 9.078.848,96

Estagiários R\$ 500.626,63

Auxílio-alimentação R\$ 3.593.857,86

Auxílio-transporte R\$227.709,15

Todavia, no que se refere aos repasses na área da educação do município de Santa Cruz do Sul, a resposta não foi satisfatória, eis que a Ouvidoria responsável tão somente informou que os dados estariam disponíveis no site do Fundo Nacional de Desenvolvimento da Educação (FNDE), na aba "Sistema de Informações sobre Orçamentos Públicos em Educação - SIOPE", na parte destinada aos relatórios municipais, mais especificamente no "Quadro de Resumo de Despesas". 0 endereço informado esteve indisponível por meses, porém, recentemente se conseguiu acesso à página, e, novamente, esta não é de fácil entendimento ao cidadão comum, não havendo a representação dos valores em forma de percentual, daqueles montantes transferidos a pessoas jurídicas e físicas, ou qualquer informação sobre entidades privadas, especificamente. Ou seja, é possível afirmar que essa resposta não se deu conforme previsões da LAI.

A Instrução Normativa do TCE-RS $n^{\circ}$ 09/2015, que elencou os vinte e dois critérios de avaliação para elaboração do Ranking da Transparência, teve como primeiro e segundo tópicos analisar se o site da Prefeitura disponibiliza o pedido de informação por meio da internet e se há relatório dos pedidos de informação (TRIBUNAL DE CONTAS DO ESTADO, www.tce.rs.gov.br). Todavia, é possível perceber que o TCE RS não fez a testagem no que se refere ao cumprimento do prazo para atendimento da solicitação previsto na LAI, mas o órgão tão somente analisou se havia a disponibilização do e-SIC nos Portais. Neste viés, cabe transcrever conclusão contida no Relatório de 2015 disponibilizado pelo TCE-RS: 
De forma complementar, o TCE-RS também avaliou a disponibilização de instrumento da transparência passiva, tendo sido constatado que 344 dos Executivos e 230 dos Legislativos disponibilizam um formulário, a ser preenchido e enviado por meio da Internet, para que o cidadão solicite acesso às informações que não encontrar no portal. Caso o pedido seja indeferido, o solicitante tem direito a recorrer da decisão de acordo com o que estabelece a Lei de Acesso à Informação (TRIBUNAL DE CONTAS DO ESTADO, www.tce.rs.gov.br, p. 54).

Portanto, nota-se aqui uma deficiência quanto ao cumprimento dos dispositivos elencados pela LAI, eis que o não atendimento da solicitação de informações e a ausência de dados claros acerca das transferências realizadas não deixa que o direito à informação fique isento de meio ardiloso que possa macular a versão mais fiel da realidade democrática, assim como deveria ser. As informações lançadas, por si só, já devem ser claras, pois são um instrumento de natureza administrativa, o qual emana do princípio da publicidade da atuação da Administração Pública, exigindo-se, assim, uma formação transparente, em decorrência da própria indisponibilidade do interesse público. Isto é, o acesso aos Portais e o atendimento pelo e-SIC são meios de viabilizar o controle social sobre a coisa pública, consequência da cidadania (BROCHETTO, SANTOS, 2014, p. 41).

\section{CONSIDERAÇÕES FINAIS}

Em um primeiro momento, já se nota uma grande dificuldade quanto a uma fiscalização eficaz dos cidadãos acerca dessa destinação de recursos públicos, bem como passa a se recear dos verdadeiros ideais das parcerias público-privadas, já que há grande chance de serem sacrificados princípios como a transparência e a inclusão dos cidadãos no processo decisório do interesse público.

Conclui-se que os Portais da Transparência (tanto o do TCE RS, quanto os das Prefeituras) não são de fácil compreensão ao cidadão comum, bem como pecam no que se refere às transferências a entidades privadas, sendo difícil interpretar o quanto cada repasse representa dentro do total gasto. Comprovou-se que o próprio órgão fiscalizador reconhece que não há atendimento satisfatório pelos municípios no que se refere às informações lançadas sobre transferências a entidades privadas, bem como não há uma padronização no lançamento dessas informações, cabendo a cada agente responsável dentro do ente municipal escolher como lançar os dados, não importando se estes são de fácil compreensão ou não.

Ainda, é necessário mencionar que, sendo as informações de exclusiva responsabilidade dos municípios que as lançam, há que se questionar se seria necessária uma fiscalização posterior das informações lançadas, a fim de se evitar a abertura de margem para manipulação de dados.

No mais, o não atendimento da solicitação feita pelo e-SIC pela maioria dos municípios, demonstra um verdadeiro descaso para com o cidadão, demonstrando inclusive que diversas vezes o acesso fica restringido a dados cadastrais e problemas técnicos dos sites, e que, mesmo se utilizando de ferramenta mais direta (e-mail), ainda não houve retorno. Assim, em não sendo 
atendidas as solicitações, resta uma sensação de distanciamento do cidadão para com as escolhas e execuções orçamentárias, impossibilitando uma participação e fiscalização democrática.

Por terem sido escolhidos os municípios considerados mais transparentes do Estado, nota-se uma falha nessa classificação, tendo em vista que a mera consulta exercida pelo cidadão não foi respondida pela grande parte dos municípios escolhidos, havendo uma grave violação à Lei de Acesso à Informação, sendo de suma importância que nas demais avaliações a serem feitas pelo órgão fiscalizador se inclua o exercício da testagem prática dos dispositivos previstos na LAl.

Com o presente estudo, fica possibilitada uma análise futura quanto a prestação de contas pelas entidades privadas que receberam os recursos públicos, se elas estão sendo publicadas de forma aberta e de fácil acesso ao cidadão, a fim deste exercer o controle social.

No mais, a pesquisa ainda não tem caráter conclusivo quanto à privatização dos serviços públicos de saúde e educação, dependendo de mais respostas para verificação de resultados abrangentes, tendo alcançado parcialmente seus objetivos. Ademais, os resultados obtidos com os municípios que atenderam ao e-SIC não constituem um padrão, restando prejudicada uma conclusão abrangente e generalizada. Porém, a hipótese restou confirmada, pois é possível já agora verificar a clara falta de transparência dos entes públicos municipais neste aspecto.

Por fim, a principal conclusão proporcionada pela presente pesquisa, é justamente a demonstração da precariedade das informações lançadas nos Portais, impossibilitando a fiscalização quanto à específica aplicação do dinheiro público que está sendo repassado às entidades privadas para prestação de serviços públicos de saúde e educação, já que a análise dos dados lançados é complexa e de difícil interpretação para o cidadão comum. Da mesma forma, conclui-se que, dentre os municípios selecionados, a solicitação de informações pelo e-SIC não é satisfatória e confiável, porque não atendida com êxito pela maioria dos entes municipais testados, o que gera grave dificuldade na fiscalização e no efetivo exercício do controle social, significando uma verdadeira afronta à participação cidadã e ao conceito de transparência pública.

\section{REFERÊNCIAS}

BRASIL. Constituição (1988). Constituição da República Federativa do Brasil. Brasília, DF: Senado Federal, 1988.

. Lei n. 12.527, de 18 de novembro de 2011. Regula o acesso à informações previsto no inciso XXXIII do art. 5o, no inciso II do § 30 do art. 37 e no $\S 20$ do art. 216 da Constituição Federal; altera a Lei no 8.112, de 11 de dezembro de 1990; revoga a Lei no 11.111, de 5 de maio de 2005, e dispositivos da Lei no 8.159, de 8 de janeiro de 1991; e dá outras providências. Disponível em: < http://www.planalto.gov.br/ccivil_03/_ato2011-2014/2011/lei/l12527.htm>. Acesso em: 03 mar. 2018.

BROCHETTO, P. C. B.; SANTOS, S. H B. A. Informação: definição e tipologia. In: ALMEIDA, H.; LEHFELD, L. S.;GUEDES, M. B (Org.). Comentários à Lei de Acesso à Informação. Santa Cruz do Sul: Essere nel Mondo, 2014. 
CONTROLADORIA-GERAL DA UNIÃO. Disponível em: < http://www.cgu.gov.br /sobre/institucional>. Acesso em: 01 mar. 2018.

DEIENNO, R.; SANTOS, S. Q. normas gerais, destinatários e princípios do acesso à informação. In: ALMEIDA, H.; LEHFELD, L. S.;GUEDES, M. B (Org.). Comentários à Lei de Acesso à Informação. Santa Cruz do Sul: Essere nel Mondo, 2014.

ESCOLA NACIONAL DA ADMINISTRAÇÃO PÚBLICA. Apresenta noções gerais institucionais. Disponível em: <http://www.enap.gov.br/pt/web/pt-br/institucional>. Acesso em: 12 jun. 2017.

FIGUEIREDO, V. S.; SANTOS, W. J. L. Transparência e controle social na administração pública. Revista Temas de Administração Pública, v. 8, n. 1, Araraquara, 2013. Disponível em:

<http://www.fclar.unesp. br/Home/Departamentos/AdministracaoPublica/ Revista Temasde AdministracaoPublica/vanuza-da-silva-figueiredo.pdf >. Acesso em: 02 jun. 2017.

NICOLA, F. S.; GUEDES, M. B.; SILVA, S. R. Procedimento da Lei $n^{\circ} 12.527 / 2011$. In: ALMEIDA, H.; LEHFELD, L. S.;GUEDES, M. B (Org.). Comentários à Lei de Acesso à Informação. Santa Cruz do Sul: Essere nel Mondo, 2014.

OUVIDORIA DO MUNICÍPIO DE FARROUPILHA. Acesso à Informação - Resposta de requerimento. [Mensagem eletrônica]. Mensagem recebida em 03 jan. 2018.

PREFEITURA DE FELIZ. Relatório de solicitações LAI 2017. Disponível em <(http://www.feliz.rs.gov.br/web/imgs/arquivos/relatorio-de-solicitacoes-lai-20171505245844.pdf>. Acesso em: 03 mar. 2018.

PREFEITURA DE SANTA CRUZ DO SUL - FINANCEIRO SAÚDE. Pedido de Acesso à informação [Mensagem eletrônica]. Mensagem recebida em 01 set. 2017.

RIO GRANDE DO SUL. Decreto n. 49.111, de 16 de maio de 2012. Regulamenta, no âmbito da Administração Pública Estadual, a Lei Federal $n^{\circ}$ 12.527, de 18 de novembro de 2011, que regula 0 acesso a informações previsto no inciso XXXIII do art. $5^{\circ}$, no inciso II do $\S 3^{\circ}$ do art. 37 e no $\S 2^{\circ}$ do art. 216 da Constituição Federal, cria a Comissão Mista de Reavaliação de Informações da Administração Pública Estadual - CMRI/RS, e dá outras providências. Disponível em: < http://www.central deinformacao.rs.gov.br/upload /arquivos/201612/ 15104457-decreto-estadual49-111-2012.pdf>. Acesso em: 12 jun. 2017.

RIQUINHO, Cláudia Lazzarotto. Governo eletrônico: uma promessa de transparência pública e consolidação democrática. Anais III Fórum Brasileiro de Pós-Graduação em Ciência Política - UFPR. Curitiba, 2013. Disponível em: <http://e-democracia.com.br /forum cienciapolitica /edicoesanteriores/2013/especific_files/papers/6MQG.pdf>. Acesso em: 23 jun. 2017. TRIBUNAL DE CONTAS DO ESTADO DO RIO GRANDE DO SUL. Relatório dos resultados obtidos a partir da avaliação dos portais dos Executivos e Legislativos Municipais do Rio Grande do Sul, 2015.

Disponível em: http://portal.tce.rs.gov.br/docs/transparencia_ 2015/relatorio_premio_boas_praticas_2015.pdf. Acesso em: 03 mar. 2018. . Resposta à solicitação $n^{\circ}$ 018457-0299/17-6 [Mensagem eletrônica]. Mensagem recebida em 21 ago. 2017. 